\title{
Eine Verschärfung der Seliwanoffschen Reaktion.
}

Von

Heinrich Rosin.

(Aus dem chemischen Laboratorium des Pathologischen Instituts der Universität Berlin.)

(Der Redaktion zugegangen am 5. Mai 1903.)

Durch folgende Modifikation gelingt es, die Seliwanoffsche Reaktion zu verschärfen und zugleich eindeutig für den Nachweis von Ketozuckern zu gestalten:

In der zu untersuchenden Flüssigkeit stellt man zunächst durch Kochen mit gleichen Teilen Salzsäure und einigen Körnchen Resorcin die Seliwanoffsche Reaktion an. Ist die charakteristische Rotfärbung eingetreten, so setzt man zu der erkalteten Flüssigkeit soviel kohlensaures Natron hinzu (in Substanz oder in Lösung), bis kein Aufbrausen mehr eintritt. Die hiernach heller, orangefarben, aber trübe gewordene alkalische Flüssigkeit wird nunmehr mit Amylalkohol kräftig ausgeschüttelt. Dieser nimmt einen roten Farbstoff auf, der einen Stich ins Gelbliche zeigt, schwach grün fluoresziert und durch Zusatz einiger Tropfen absoluten Alkohols rein rosarot wird. Der Farbstoff gibt ein sehr charakteristisches Spektrum auch bei erheblicher Verdünnung. Dünne Lösungen zeigen einen einzigen Streifen im Grün bei der Linie $\mathrm{E}$ bis hin zu b; etwas konzentriertere Lösungen zeigen diesen Streifen sehr dunkel und über beide Linien etwas hinausgehend, sowie schärfer begrenzt, und außerdem noch einen zweiten schwachen und unscharf begrenzten im Blau bei der Linie F. Konzentrierte Lösungen absorbieren das Spektrum vom Grün an. Ein Zusatz von Alkohol, welcher die Farbe, wie erwähnt, von rotgelb in rosarot verwandelt, bewirkt auch ein schärferes 
Hervortreten des Streifens im Grün. Umgekehrt kann man die spektroskopischen Streifen gänzlich aus der amylalkoholischen Lösung des Farbstoffes herausbringen, wenn man sie mehrfach gründlich mit destilliertem Wasser ausschüttelt, wobei gleichzeitig die Färbung des Amylalkohols sich in gelbrot verwandelt. Fügt man nach dem Auswaschen jeder Spur von Alkali etwas Alkohol hinzu, so tritt kein Streifen mehr auf. Derselbe kehrt aber wieder, wenn man den Amylalkoholextrakt mit Sodalösung schüttelt, wobei gleichzeitig die alte rote, schwach grün fluoreszierende Färbung auftritt. Verdunstet man die gut gewaschene, amylalkoholische Lösung auf dem Wasserbade, so läßt sich der farbige Rückstand mit Alkohol aufnehmen. Derselbe löst sich in Alkohol mit gelbroter Farbe und gibt nach Zusatz von kohlensaurem Natron wieder das Spektrum des Farbstoffs, dessen weitere Untersuchung ich mir vorbehalte.

In der so angegebenen Modifikation ist die Reaktion äußerst empfindlich und zugleich charakteristisch nur für Ketosen, von denen ich außer Fructose noch Sorbose untersuchte. Auch das salzsaure Glucosamin zeigte die Reaktion (schwach), entsprechend einerBeobachtung Friedrich Müller s. ${ }^{1}$ ) Und sie gestattet, anderweitige Rotfärbungen, die beim Kochen anderer Substanzen mit Salzsäure und Resorcin entstehen, von denjenigen zu unterscheiden, welche die Ketosen ergeben, da bei der angegebenen Behandlung das typische spektroskopische Bild nicht auftritt.

Die Reaktion dürfte daher an Stelle von zeiţraubenderen Darstellungsmethoden von Fruchtzucker als einwandsfrei dann zu empfehlen sein, wenn es sich nur um qualitativen Nachweis von Fruchtzucker und anderen Ketozuckern handelt.

1) Zeitschr. f. Biologie, Bd. 42, 1901, S. 511. 